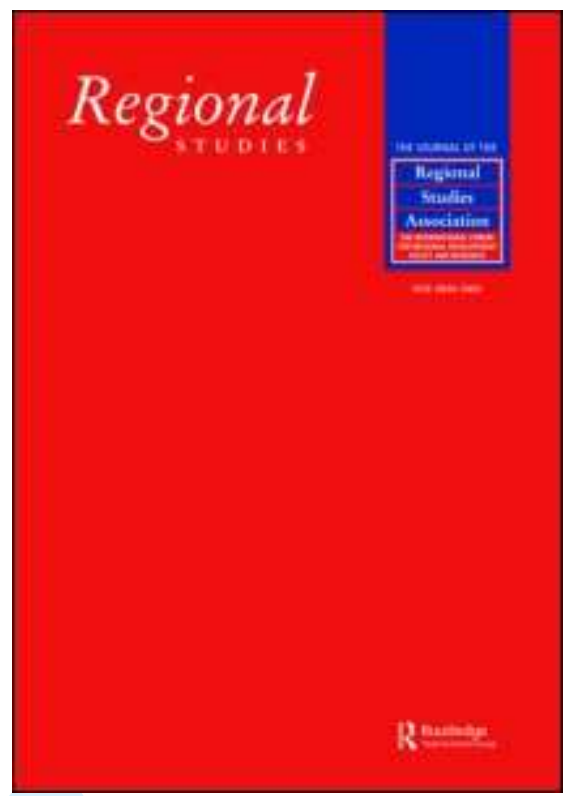

\title{
Concentration of Manufacturing and Service Sector Activities in Italy: Accounting for Spatial Dependence and Firm Size Distribution
}

\begin{tabular}{|r|l|}
\hline Journal: & Regional Studies \\
\hline Manuscript ID: & CRES-2007-0361.R3 \\
\hline Manuscript Type: & Main Section \\
\hline JEL codes: & $\begin{array}{l}\text { C12 - Hypothesis Testing < C1 - Econometric and Statistical } \\
\text { Methods: General < C - Mathematical and Quantitative Methods, } \\
\text { R12 - Size and Spatial Distributions of Regional Economic Activity } \\
\text { R1 - General Regional Economics < R - Urban, Rural, and Regional } \\
\text { Economics, R30 - General < R3 - Production Analysis and Firm } \\
\text { Location < R - Urban, Rural, and Regional Economics }\end{array}$ \\
\hline Keywords: & $\begin{array}{l}\text { Geographic Concentration, Exploratory Spatial Data Analysis, } \\
\text { Spatial Autocorrelation, Italy }\end{array}$ \\
\hline \multicolumn{2}{|c}{} \\
\hline
\end{tabular}

\section{SCHOLARONE \\ Manuscripts}




\title{
Concentration of Manufacturing and Service Sector Activities in Italy: Accounting for Spatial Dependence and Firm Size Distribution
}

\author{
Authors: \\ Laura de Dominicis \\ Affiliation: European Commission, JRC-IPTS, Seville \\ Full address: European Commission JRC-IPTS, C/Inca Garcilaso 3, 41092 Seville, Spain \\ Email: laura.de-dominicis@ec.europa.eu
}

Giuseppe Arbia,

Affiliation: Universitá degli Studi "G. d'Annunzio", Pescara

Full Address: Universitá degli Studi "G. d'Annunzio", Viale Pindaro 42, 65127, Pescara, Italy

Email: arbia@unich.it

Henri L.F. de Groot

Affiliations: VU University Amsterdam, Tinbergen Institute Amsterdam-Rotterdam, and Ecorys NEI

Full address: Department of Spatial Economics, VU University Amsterdam, De Boelelaan 1105, $1081 \mathrm{HV}$, Amsterdam, The Netherlands

Email: h.1.f.de.groot@vu.nl

(Received December 2007: in revised form March 2011) 


\begin{abstract}
The empirical analysis of the spatial distribution of economic activity on a discrete space is based on measures that suffer from a series of drawbacks. We propose a methodological advance in two respects. First, we extend the analysis to take spatial dependence explicitly into account. Second, we control for differences in the size distribution of firms between territorial units. Using data for Italy, we apply exploratory spatial data analysis to identify sectoral location patterns in both the manufacturing industry as well as in the business services. We find that large differences prevail in the geographical concentration of production across sectors.

JEL codes: $\mathrm{C} 12, \mathrm{R} 12, \mathrm{R} 30$

Keywords: Exploratory Spatial Data Analysis, Firm size distribution, Geographic concentration, Spatial autocorrelation, Italy
\end{abstract}




\section{INTRODUCTION}

Agglomeration economies play an important role in explaining regional development, regional growth and industrial location. New Economic Geography theories have substantially contributed to stimulate the revival of interest in the empirical description and explanation of industrial patterns of agglomeration (KRUGMAN, 1991; FUJITA and THISSE, 2009). A number of forces - also referred to as localization economies - make it advantageous for firms in the same industry to locate in close proximity (cf. MARSHALL, 1890). Geographical proximity eases communication, facilitates technological spillovers between firms in the same industry, induces efficient provision of intermediate inputs at a lower cost, and allows firms to share a larger market for inputs and outputs, in particular a local skilled labour pool.

In recent years, a great number of studies have analyzed the spatial distribution of economic activity in Europe. ${ }^{1}$ We can distinguish between at least three generations of studies (cf. COMBES and OVERMAN, 2005). A first generation used Gini-type measures of geographical concentration where space and firm size are not taken into consideration (for example, KRUGMAN, 1991). A second generation (ELLISON and GLAESER, 1997; MAUREL and SEDILLOT, 1999; DEVEREUX et al., 2004) introduced measures that tend to control for the underlying structure of the industry and extends previous approaches to include establishment-size effects within industries. These first two types of measures are all based on the distribution of economic activity over discrete territorial units. A third generation of studies differs from the previous ones in that the proposed measure of agglomeration is calculated looking at plants as points in continuous space (ARBIA, 2001; DURANTON and OVERMAN, 2005; ARBIA et al., 2008). This approach has the advantage of avoiding aggregating information to the level of discrete spatial units, but it 
requires location data at the level of individual establishment within each industry, and such data are oftentimes not available, in particular at the national level. It has been therefore mostly applied to the study of industrial location at the sub-national level.

ARBIA (2001) and, more recently, GUILLAIN and LE GALLO (2010) amongst others raised the point that traditional measures of geographical concentration do not offer any information on the location patterns, that is, where and how the agglomeration process takes place. There is the need to jointly consider the degree of spatial agglomeration of economic activity without ignoring the importance to identify location patterns, since they are complementary to each other. ${ }^{2}$

This paper extends the approach taken in GUILLAIN and LE GALLO (2010) by also including firm size and contributes to the empirical literature on industrial location by proposing a novel approach to jointly assess industry location and density patterns in a discrete space, taking into consideration differences in the size distribution of firms. We investigate spatial patterns in the distribution of economic activities in Italy paying explicit attention to spatial dependencies that may arise among territorial units. Furthermore, in order to include establishment-size effects within each industry, we use the adjusted form of the location quotient proposed by O'DONOGHUE and GLEAVE (2004).

The proposed approach is used to analyse the spatial pattern of employment in Italy of 41 industries in the manufacturing and business service sectors (from now onwards simply referred to as service sectors). Italy represents an interesting case study for a number of reasons. First, the country has a peculiar industrial structure characterised by the presence of a small number of densely populated industrial clusters. Such clusters are oftentimes composed of industries of small size. A second important advantage comes from the richness of our dataset, which allows us to measure geographic concentration across a large 
number of regions (about 680) and a comprehensive number of industrial sectors. Continuous space modelling would have been the optimal choice for dealing with the micro-foundations of agglomeration. However, to our knowledge, firm data at the microlevel encompassing the whole territory of Italy are not available, largely for reasons of confidentiality. For our empirical analysis, we have therefore focused on regionally aggregated data, focusing the analyses on a rather fine partition of Italy into 680 functional regions and covering a total of 41 industrial sectors at the NACE-2 level.

The paper is structured as follows. The next section presents and characterizes the data. We then analyze agglomeration of manufacturing and service industries in Italy. The subsequent section extends the analysis to account for spatial dependence, where both global and local spatial dependence are considered. And the paper concludes with a summary and reflection.

\section{DESCRIPTION OF THE DATA}

Our analysis rests on a large dataset containing data on the number of employees and the number of plants of all Italian firms in Italy for the years 1991 and 2001. The industry is defined at the NACE 2-digit sector level, and the data refer to 24 manufacturing sectors (including construction) and 17 service sectors. ${ }^{3}$ The Italian National Statistical Office (ISTAT) runs on regular intervals census surveys on the industry and the service sectors. The dataset provides detailed information both at a geographical (around 8,100 Italian municipalities) and industrial level (up to 3-digit NACE industries). ${ }^{4}$ The choice of the level of industrial aggregation is very determining in observing concentration and spatial patterns, as well as the level of territorial aggregation. A recent meta-analysis reports that the level of regional aggregation is also highly relevant, especially for the strength with 
which the agglomeration forces are operational (DE GROOT et al., 2009). We therefore decided to focus our analyses on the distribution of employment to a level of industry aggregation at the NACE-2 level, giving ample space in the analyses to the effect of different partitions of the space to the spatial distribution of economic activity.

Employment is measured at the level of functional regions. A functional region is a territorial unit that is defined and classified by looking at patterns of spatial interaction or spatial organization, and in which there is an overall coherence to the structure and dynamics of political, economic, and social organization. We can therefore circumvent the use of administrative units which is attractive for two major reasons. First, administrative boundaries are static and are usually the resultant of historical, political, and social events. Second, economic clusters and polarisations oftentimes exist at spatial scales that go beyond the traditional administrative boundaries, as in the case of the Italian Industrial Districts. In Italy the concept of functional regions has been used to identify a large number of Local Labour Market Areas, known as Local Labour Systems (LLSs), which are defined on the basis of minimum daily commuting patterns, so as to maximize the coincidence between residential and working areas. ${ }^{5}$ The Italian National Statistical Office updates the number of the LLSs every ten years. For the sake of comparability, we consider in our analysis the territorial subdivision of Italy in LLSs according to the 2001 classification and we apply it also for data of $1991 .^{6}$

The Italian industrial structure is characterised by the presence of a large number of micro-firms, both in the manufacturing and in the service sectors. In 2001 , about 80 per cent of Italian manufacturing firms in our dataset have less than 10 employees, while more than 90 per cent of firms in the service sector employ less than 10 workers. 


\section{GEOGRAPHIC CONCENTRATION OF ECONOMIC ACTIVITIES IN ITALY}

We first measure the geographical concentration of manufacturing and service sectors in Italy for the years 1991 and 2001 using the measure introduced by ELLISON and GLAESER (1997). This measure has two main advantages. First, it builds on a rigorous statistical model in which a situation of random distribution of economic activities across the spatial units is taken as a benchmark. Furthermore, the index corrects for the upward bias induced by the presence of industries consisting of few relatively large plants. The main disadvantage of the index is in its inherently a-spatial nature. Once the measure finds support to the fact that an industry is geographically concentrated, it does not give further information on whether concentration occurs across areas that are close together or far apart. This point was first raised by ARBIA (2001). Moreover, the index is not robust to variations in the size of the spatial unit (BERTINELLI and DECROP, 2005; DURANTON and OVERMAN, 2005).

The Ellison and Glaeser (EG) measure of geographical concentration is defined as follows: ${ }^{7}$

$$
\hat{\gamma}_{E G} \equiv \frac{\left(s_{i}-x_{i}\right)^{2}-\left(1-\sum_{i=1}^{N} x_{i}^{2}\right) H}{\left(1-\sum_{i=1}^{N} x_{i}^{2}\right)(1-H)}
$$

where $s_{1}, s_{2}, \ldots, s_{N}$ are the share of an industry's employment in each of the $N$ LLSs, $x_{1}, x_{2}, \ldots, x_{N}$ are the share of total employment in those areas, and $H$ is the Herfindahl index of plants' size distribution. Under the null hypothesis of random localization of the plants, the expected value of the measure is zero, with any positive value of the index interpreted as evidence of localization. ${ }^{8}$ Testing the statistical significance of the index indicates 
whether a sector's distribution of activity across locations is significantly concentrated or dispersed in a statistical sense. ${ }^{9}$

\section{The concentration of 2-digit manufacturing and service industries in Italy}

We computed the EG index for each of the 2-digit manufacturing and service industries in our dataset. ${ }^{10}$ Previous studies have observed that the scale of the territorial units may influence the degree to which industries are found to be concentrated (ELLISON and GLAESER, 1997; MAUREL and SEDILLOT, 1999; LAFOURCADE and MION, 2007; ALECKE et al., 2006). We find that there is a strong tendency of the index to increase at the higher level of aggregation of the territorial units (comparing results for Italian functional regions, provinces and regions). ${ }^{11} \mathrm{~A}$ reason for this may be the existence of spatial autocorrelation between local labour systems, which the index is not able to capture. Thus, computing the Ellison-Glaeser index at a higher level of spatial aggregation is partly internalizing positive spatial autocorrelation, leading to a higher concentration (DEVEREUX et al., 2004; LAFOURCADE and MION, 2007).

[Insert Table 1 around here]

Fig. 1 shows the overall distribution of EG indices in 1991 and 2001 for the whole set of industrial sectors. On the horizontal axis are the values of the EG for each of the sectors in our dataset. Reference values for weak localization (values below 0.02), localization (between 0.02 and 0.05 ) and strong localization (above 0.05) are also displayed (ELLISON and GLAESER, 1997). On the vertical axis are percentages. The pictures for both years are 
strongly skewed, with the majority of the industries being moderately localized to localized. About 15 per cent of industries appear to be strongly localized.

[Insert Fig. 1 around here]

Given the overall pattern of concentration revealed by Fig. 1, we further develop our discussion around the geographical concentration in the 15 most localized 2-digit industries across LLSs. Figures are presented in Table 2. We first analyze how industrial agglomeration evolved over time. Among the 15 most localized industries, only the Tobacco Industry, Manufacture of Non-Metal Products, and Manufacture of Other NonMetallic Mineral Products are not among the most concentrated industries in both years. In all other cases, the same industries appear to be among the most concentrated both in 1991 and in 2001. The stability in the concentration level observed in most Italian industries is a pattern also found in other countries (DUMAIS et al., 2002, for the US; DEVEREUX et al., 2004, for the UK; ALONSO-VILLAR et al., 2004, for Spain). Among the most concentrated industries is the Manufacture of Motor Vehicles, although the degree of concentration has noticeably declined in the 1990s. This result can be explained if we consider that the largest part of the production of motor vehicles in Italy is carried out by one single firm (FIAT) which concentrates its activity in a small number of plants (that is, Turin in Piemonte, Termini Imerese in Sicilia and Melfi in Basilicata). ${ }^{12}$ If we look at the sectors with the highest degree of concentration, we can identify two distinct groups of industries; in both groups operate a large number of small and medium sized enterprises. The first group includes a number of high-tech industries such as Manufacture of Office Machinery and Computers, Manufacture of Chemicals, and Manufacture of Radio, 
Television, and Communication Equipment. As pointed out in MAGGIONI (2002), Italian high-tech clusters are somehow different from those in other countries. In general, they are made up of small and medium-sized enterprises that are characterized by a lower level of technology adoption. In a second group, we find traditional activities in which the weight of small and medium-sized enterprises is also very high, such as Manufacture of Textile and Tanning and Dressing of Leather. These are industries operating in a well-defined area of the country, the so-called 'Third Italy'. ${ }^{13}$ In a number of sectors where small firms predominated, groups of firms which are clustered together in specific regions seemed to be able to grow rapidly, to develop niches in export markets and to offer new employment opportunities.

Among the service industries, Research and Development, Computer and Related Activities and Insurance and Pension Funding show the highest level of concentration. Different from manufacturing, these industries tend to concentrate in dense urban areas, where a pool of high-qualified workers is available, and where the high costs associated with the services offered may be divided among a larger number of potential customers.

[Insert Table 2 around here]

\section{SPATIAL DEPENDENCIES IN THE DISTRIBUTION OF ECONOMIC ACTIVITIES IN ITALY}

\section{Global spatial dependence}

The concentration index employed in the previous section provides useful information about the extent to which industries in Italy are concentrated in a limited number of areas, http://mc.manuscriptcentral.com/cres Email: regional.studies@fm.ru.nl 
but it does not take into consideration whether those areas are close together or far apart. Two industries may appear equally geographically concentrated, while one may be located in two neighbouring regions, whereas the other may split between the northern and the southern part of the country. As such, this measure suffers from the same shortcoming as other traditional indices of geographical concentration in that it is inherently a-spatial (ARBIA, 2001).

Various alternatives are possible. Some papers suggest to compute simultaneously both a-spatial and spatial measures of concentration in order to discriminate between different geographical patterns (ARBIA, 2001, or GUILLAIN and LE GALLO, 2010). A second alternative is to derive a composite index which accounts for both aspects together as suggested by PIRAS and ARBIA (2009). MIDELFART-KNARVIK et al. (2004) propose an index of spatial separation that takes into account distances between locations. LAFOURCADE and MION (2007) quantify the degree of spatial agglomeration in the Italian manufacturing industries using a measure of spatial agglomeration where proximity is expressed in terms of minimum road distances among pairs of locations. A related approach, based on Exploratory Spatial Data Analysis (ESDA), is employed in GUILLAIN and LE GALLO (2010) in order to investigate employment location patterns in the manufacturing and service sectors in the metropolitan area of Paris and its surroundings.

In what follows we investigate the issue of spatial dependence in the distribution of industrial employment across LLS areas. The literature has provided a number of indicators to distinguish amongst various cases of spatial dependence. In the following analyses we use the Moran's $I$ index of spatial autocorrelation to test for the presence of spatial dependence in our data (MORAN, 1950). 
The point of departure is the Adjusted Location Quotient proposed by O'DONOGHUE and GLEAVE (2004). This is a relative measure of agglomeration. In the literature on agglomeration there is a lively debate about the accurate choice between absolute and relative measures of agglomeration (HAALAND et al., 1999; BRÜLHART and TRAEGER, 2005; MORI et al., 2005). Depending on the purpose of the study, one measure or the other could be the correct one. If one is mainly interested in revealing regional comparative advantages and specialisation (as in our case) then a measure of relative concentration is to be preferred; but if one, for instance, thinks about scale economies and trade, then the relevant measure is the absolute concentration of production (HAALAND et al., 1999; AIGINGER and DAVIES, 2004).

In a similar fashion as the EG index, the measure proposed by O'DONOGHUE and GLEAVE (2004) is able to discriminate between those areas which have a large number of firms of small and medium size (SME), and those where the same number of workers is employed by one single or only few large firm. Clusters of small and medium-sized enterprises are at the core of Italian industrial structure. According to the latest empirical data (ISTAT, 2006) SMEs in Italy are about 99 per cent of all industries, they employ 81 per cent of Italian workforce and produce about 70 per cent of the national value-added.

Using Italian manufacturing data, LAFOURCADE and MION (2007) examine the influence of plant size on plant location choices and find strong evidence of a different behaviour when considering separately large plants and small plants. CAMAGNI and CAPELLO (1999), among others, have highlighted the important role of small firms in determining regional development in Italy. In particular, for these firms, the role of colocation, in combination with specific territorial features, play a major role in shaping the performance of regional industrial systems, where a different innovation path emerges, 
relying on informal relationship with the external environment. Moreover, as noted by GUILLAIN and LE GALLO (2010), while clusters of different firms suggest that agglomeration forces are at work, the presence of a single large firm does not. Having a measure that produces a value for each sector and in each region and accounts for the firm size is undoubtedly the strong point of the method we propose. It allows identifying spatial patterns in the distribution of employment at the sectoral level.

The Adjusted Location Quotient proposed by O’DONOGHUE and GLEAVE (2004) is defined as:

$$
\operatorname{AdjL} Q_{s, i}=\frac{e_{s f_{s, i}} / \sum_{s} e_{s, i}}{\sum_{i} \sum_{s} e_{s f_{s, i}} / \sum_{i} \sum_{s} e_{s, i}}
$$

where the numerator represents the share of employment in small firms in sector $s$ in region $i$ over the total regional employment in sector $s$. The denominator measures the share of total national employment in small firms over total national employment. We run our exercise on two definitions of small firms, based on less than 10 employees and less than 50 employees and compare the results with the results produced by the standard version of the Location Quotient. The Standard Location Quotient, as defined in KIM (1995), is:

$$
L Q_{s, i}=\frac{e_{s, i} / \sum_{i} e_{s, i}}{\sum_{s} e_{s, i} / \sum_{i} \sum_{s} e_{s, i}}
$$

where the numerator measures the share of employment in sector $s$ in region $i$ with respect to the total employment in Italy in sector $s$, and the denominator is the share of total employment in region $r$ with respect to the total employment in Italy

The Moran's I coefficients of spatial autocorrelation (MORAN, 1950) are then obtained using as variable of interests the $N$ values of the (Adjusted) Location Quotients 
relative to each sector $s$ and each location $i$. Formally, for each of the sectors in our sample, the Moran's I equals:

$$
I_{s}=\frac{N}{\sum_{i=1}^{n} \sum_{j=1}^{n} w_{i j}} \frac{\sum_{i=1}^{n} \sum_{j=1}^{n} w_{i j}\left(x_{i}-\bar{x}\right)\left(x_{j}-\bar{x}\right)}{\sum_{i=1}^{n}\left(x_{i}-\bar{x}\right)^{2}}
$$

where $N$ is the total number of functional regions, $i$ and $j$ denote a pair of distinct LLS, $x_{i}$ and $x_{j}$ are the observed values in regions $i$ and $j$ of the location quotients as defined in equations (2) and (3) (with mean $\bar{x}$ ), and the first term is a scaling constant. This statistic compares the value of a continuous variable at any location with the value of the same variable at surrounding locations. The spatial structure of the data is formally expressed in a spatial weight matrix W (CRESSIE, 1991; ANSELIN, 1988) with generic elements $w_{i j}$ (with $i \neq j) .{ }^{14}$ Since the size of our territorial units is not homogeneous, the use of a weight matrix based on distance or contiguity is likely to lead to a very unbalanced connectedness structure. A commonly used alternative consists of considering nearest neighbours weight matrices. Nearest-neighbour matrices imply that each spatial unit is connected to the same number $k$ of neighbours. Since the average number of first-order contiguity neighbours in our sample of regions is 5.2 , we use a 5-nearest neighbours weight matrix. ${ }^{15}$ The results of the Moran's I statistics of the 15 more agglomerated industries in 2001 are listed in Table 3, both for the standard LQ and for the adjusted-LQ. ${ }^{16}$ A first remarkable feature is that over the years, with the exception of few sectors, the 15 highest positions in the ranking have been occupied by the same industries. The ranking across measures presents some differences, but we observe that a large number of sectors appear in all three rankings. The standard LQ and the Adj-LQ with threshold at 50 employees produce very similar results. This is not surprising as firms with more than 50 employees are not a large number in Italy. 
[Insert Table 3 around here]

\section{Local spatial patterns in the distribution of economic activities in Italy}

The traditional Moran's I measure of spatial autocorrelation that we used so far is a global measure able to capture the overall spatial pattern in the data and to summarize it in a single statistic. When studying the spatial distribution of production activity in space, significant spatial autocorrelation is likely to occur only for a subset of regions. A positive measure of global autocorrelation captures the existence of both high-value clustering and low-value clustering, while a negative autocorrelation captures the juxtaposition of high-values next to low-values. In other words, only one dominant type of autocorrelation can be detected. If two structures, such as high-value clustering and low-value clustering, coexist, Moran's $I$ cannot distinguish them (LE GALLO and ERTUR, 2003; ZHANG and LIN, 2007). In contrast, local indicators of spatial association (or LISA) are specifically designed to find evidence of local spatial patterns in the empirical data (ANSELIN, 1995). These indicators allow for the decomposition of global indicator, such as Moran's $I$, into the contribution of each individual observation. LISA, when coupled with other exploratory spatial dataanalysis tools such as Moran's I cluster map or scatter plot, can be used to detect local spatial associations, such as high-value clusters, low-value clusters, and negative autocorrelations. In what follows, we measure local spatial dependence using the local version of the Moran's I statistic described before. The local Moran's I yields a measure of spatial autocorrelation for each individual location and is designed to test whether the distribution of values around that specific location deviates from spatial randomness. Local indicators of spatial association can be used for the detection of significant local spatial 
clusters (also called 'hot spots') as well as for diagnostics of local instability, significant outliers and spatial regimes. ${ }^{17}$ The local Moran statistic for an observation $i$ is defined as (ANSELIN, 1995):

$$
I_{i}=x_{i} \sum_{j \neq i} w_{i j} x_{j}
$$

where the $x_{s}$ 's are the values of the Adjusted Location Quotient. For ease of interpretation, the weights $w_{i j}$ are row standardized and by convention $w_{i i}=0$. As before, the spatial ordering is defined using a 5-nearest neighbours weight matrix. We illustrate the results using a cartographic representation - the local Moran's I cluster map - in which the significant values of the local Moran are classified as: $\mathrm{HH}$ for locations with high levels of the location quotient for a specific sector surrounded by regions with high levels of the location quotients (in red); LL for locations with low levels surrounded by locations where the location quotients are also low (in dark blue); HL for locations with high values surrounded by locations with low values (in pink), and LH for locations with low values surrounded by locations with high values (in light blue). While the first two typologies (namely $\mathrm{HH}$ and LL) suggest clustering of similar values, the last two situations (HL and LH) capture the presence of regional outliers in the spatial distribution of economic activities. By comparing results for the manufacturing and the service sector we observe that while for the former, agglomeration is in the majority of the cases characterised by the clustering of contiguous local labour market areas in which one sector is concentrated, employment in the service sector appears to be concentrated within the local unit itself, only in few cases - i.e. Post and Telecommunications, Real Estate Activities, and the two Wholesale sectors - spreading outsides to neighbouring areas. Moreover, the spatial distribution of employment in the service sectors appear to be more scattered across the territory, in close proximity of populated urban areas. 
In what follows, we comment in more detail on the results for a selection of sectors: Manufacture of Textile, Manufacture of Motor Vehicle, Financial intermediation, and Activities auxiliary to financial intermediation. ${ }^{18}$ The choice of the sectors is motivated by the different situations they represent of: (i) a sector in which a large number of small firms concentrate in specific areas (Manufacture of Textile), (ii) a sector where one or two large firms employ most of the labour and are surrounded and supported in their activity by a large number of small and very small firms in charge of providing services and intermediate goods (Manufacture of Motor Vehicle); and finally (iii) sectors in which different spatial patterns emerge, any each of them populated either by medium and large firms or by very small firms (Financial intermediation, and Activities auxiliary to financial intermediation).

Fig. 2-Fig. 5 illustrate the results. In each map, the figure at the top displays the local Moran's I cluster map based on the standard definition of the Location Quotient. The figures at the bottom represent the local Moran's cluster map for the Adjusted Location Quotients, with thresholds at 50 and 10 employees. It is interesting to jointly consider the three maps, in order to fully understand the value added of the proposed methodology, able to depict whether agglomeration emerges because of the presence of many small firms or because of the existence of a single large firm. We observe that the Moran's I cluster map relative to the Standard Location Quotient fail in identifying patterns of agglomeration in sectors where a large number of small firms operate. For instance, in the first sector Manufacture of Textile - operate mostly small firms belonging to the traditional manufacturing sector (Fig. 2). ${ }^{19}$ The production in this sector tends to be organized in industrial districts, ${ }^{20}$ where companies establish close relationships which contribute to the creation of the competitive success: on the one hand strong competition stimulates product 
innovation; on the other hand, proximity and a high level of specialization allow for a continuous transmission of knowledge. This produces not only a high level of flexibility, but also enables the economies of scale typically found in large companies to be achieved through productive integration. The sector concentrates in the centre-north of Italy, mostly in the areas of Biella, Carpi and Prato, where the bigger firms operate. However, production in this sector is not limited to those areas. When we consider the contributions of small firms to the sector, we observe a concentration of employment that the standard LQ was not able to detect.

Fig. 3 illustrates the spatial patterns in the employment in the Manufacture of Motor Vehicles sector. This is a typical sector where traditionally most of the production in Italy is in the hands of one single big company. The traditional LQ, indeed, identify agglomeration only in those areas where FIAT group, the largest vehicle manufacturer in Italy, has its plants. However, the existence of such of a big firm has alimented the growth of a large number of small firms providing intermediate products and services. If we consider the spatial pattern produced by the Adjusted LQ, in particular with threshold at 10 employees, we observe an agglomeration of small firms in areas bordering the region where the FIAT group has its own plants.

Fig. 4 and Fig. 5 show results for two service sectors, Financial intermediation, and Activities auxiliary to financial intermediation. In the service sector, contrary to what we found before in the manufacturing, we find some differences in the spatial patterns of employment across the different specifications of the LQs, although, in our opinion, not as substantial as for the manufacturing.

Examination of the other sectors clearly show that while exploratory spatial data analysis provides a valid tool for the identification of spatial patterns in the distribution of 
economic activity, it might fail - by ignoring differences in the size distribution of the firms - identifying specific situations where multiple location patterns emerge in those sectors where both small and large firms operate. We can distinguish between two situations. On the one hand, there are sectors in which employment tend to concentrate in the same regions, independently from the size distribution of the firms. ${ }^{21}$ This might suggest that for those sectors firms of different size tend to locate in close proximity, where small and large firms take advantage from the presence of knowledge spillovers and live in a state of symbiosis advantageous to both, with the small units, for instance, acting as subcontractors of the large firms. On the other hand, we have situations where, within the same sector, different location patterns emerge, and they are strictly linked to the size of the firms. ${ }^{22}$ The intensity of transport costs between small and large firms has been presented as a plausible explanation of the different location choices where large firms, often more internationallyoriented, tend to locate in areas with a better access to the foreign market, while small firms, more oriented to the local market, are more interested in inter-regional linkages, would need to save on transport costs by locating in close proximity to domestic demand (LAFOURCADE and MION, 2007).

[Insert Fig. 2-5 around here]

\section{CONCLUSIONS}

In this paper we contribute to the empirical literature on the spatial distribution of economic activities by taking firm size distribution and spatial dependence among territorial units explicitly and jointly into account. We do so elaborating on the seminal work by ELLISON and GLAESER (1997), who have accounted for firm size distribution, but neglected the 
spatial structure inherent in the data. Based on previous empirical studies on industrial location, we propose a methodology that jointly considers the effects of spatial dependence and firm size in order to measure industrial spatial agglomeration.

Spatial agglomeration is a very complex subject due to the many different facets that it presents. A first problematic aspect concerns the issue of a-spatial versus spatial concentration. Measures like Gini, Ellison-Glaeser, Herfindal, Location Quotients and others consider only the amount of the observed variable and not where it is located in space. In other words they are robust to spatial permutations. This problem was noted by ARBIA (2001) and different solutions have been proposed in the literature. Under this respect GUILLAIN and LE GALLO (2010) proposed to supplement a global spatial analysis with a local analysis based on LISA and other ESDA methods. However, they neglect a second important aspect which is also of paramount importance when studying spatial agglomeration that has to do with firm dimension. In fact a high value in the agglomeration measures may be produced by a large number of small firms located nearby, but also, alternatively, by just a small number of very large firms clustering together. Obviously the two typologies of agglomeration are very different in terms of the consequences on regional development. They also lead to dramatically different interpretations if the researcher is interested in understanding the forces driving spatial agglomeration (FUJITA and THISSE, 2002). This second aspect related to firm dimension has been taken into consideration in studies like, for example, O'DONOGHUE and GLEAVE (2004) when analysing regional clusters. In the quoted paper the authors suggest to correct the traditional LQ indices to account for the different firm size. However they neglected the effect of spatial dependence. 
The contribution of this paper is to consider both of the above problematic aspects in the same analysis. More specifically, in this paper we used the adjusted version of the location quotient proposed by O'DONOGHUE and GLEAVE (2004) to account for the different firm dimension and some exploratory spatial data analysis techniques to identify spatial pattern in the distribution of employment in the manufacturing and service sectors in Italy. The methodology we propose proved useful for the economic analysis of spatial clusters in countries or regions where economic activity is mostly performed by small-sized firms. Moreover, it allows to empirically verify whether the size distribution of firms is relevant in explaining episodes of agglomeration and differences across sectors. We observe that large and persistent differences exist in the geographical concentration of industry employment across sectors. We show that in a country like Italy where a large number of small firms operate, traditional methods used to identify industrial agglomeration are not able to control for the contribution of small firms to the overall patterns of industrial agglomeration. The method we propose is straightforward in its application and is not demanding in terms of data. Future research could focus on the use of a finer level of aggregation of industries (for instance at the NACE-3 level), and the analysis of spatial patterns and determinants of industry co-agglomeration, by examining which industries locate near one another (ELLISON et al., 2010).

Acknowledgements - The authors thank the editor and three anonymous referees for insightful comments. The usual disclaimer applies. The first author acknowledges financial support from the European Union's Sixth Framework Programme for Research and Technological Development. The views expressed are purely those of the author and may 
not in any circumstances be regarded as stating an official position of the European Commission.

\section{ENDNOTES}

${ }^{1}$ A good summary of the main results can be found in COMBES and OVERMAN (2004).

${ }^{2}$ Some other authors employ a rather different approach, which is not based on the standard concentration measures, but aims at studying the spatial clustering of activities in a continuous space. Such an approach was introduced by ARBIA and ESPA (1996) and subsequently exploited by, amongst others, MARCON and PUECH (2003) for France, QUAH and SIMPSON (2003) and DURANTON and OVERMAN (2005) for the clustering of industries in the UK and by ARBIA et al. (2008) for the co-agglomeration of high-tech industries in Italy.

${ }^{3}$ An Annex with the complete set of the sectors in the dataset is available online.

4 Starting from a dataset at the municipal level, we aggregate the data into larger administrative units (more specifically, NUTS-3 and NUTS-2 regions) and into functional regions (local labor market areas, or LLMAs). Results for the NUTS regions are available online.

5 The European Commission has recently recognized the central role of the LLSs. Following a period of negotiation between the European Authorities and the Italian Government the LLSs have become the territorial units used by the EU to identify the areas eligible under the Objective 2 in the Northern and Central regions of Italy for the 20002006 programming period (Commission Decision 2000/530/EC of the 27 July 2000). 
${ }^{6}$ We are aware that the choice of spatial units might influence some of the results on agglomeration since the definition of LLS is based on daily commuting flows. A sector is more likely to be found agglomerated if it is largely dominant in a dense area of commuting. However, we believe that for the purpose of our study they are still the most appropriate geographical units as they rely on real economic features. They reflect, as closely as possible, commuting fields of what can be considered a local economy and they are far less arbitrary than administrative units (O’DONOGHUE and GLEAVE, 2004).

${ }^{7}$ For details on the derivation of the measure of geographical concentration, see ELLISON and GLAESER (1997).

${ }^{8}$ Ellison and Glaeser show that the expected value of this measure is zero if plants are randomly located, with any positive value of the index interpreted as localization. In particular, values between 0 and 0.02 are interpreted as weak localization, and anything above 0.05 as a strong tendency to localize (ELLISON and GLAESER, 1997)

${ }^{9}$ As shown in ELLISON and GLAESER (1997) and MAUREL and SEDILLOT (1999), the variance of the estimator under the null hypothesis of no spillovers $\gamma=0$ is given by: $\operatorname{var}\left(\hat{\gamma}_{E G}\right)=\frac{2(1-H)^{2}}{\left(1-\sum_{i=1}^{M} x_{i}^{2}\right)} H^{2}\left(\sum_{i=1}^{M} x_{i}^{2}-2 \sum_{i=1}^{M} x_{i}^{3}+\left(\sum_{i=1}^{M} x_{i}^{2}\right)^{2}\right)-\sum_{j=1}^{N} z_{j}^{4}\left(\sum_{i=1}^{M} x_{i}^{2}-4 \sum_{i=1}^{M} x_{i}^{3}+3\left(\sum_{i=1}^{M} x_{i}^{2}\right)^{2}\right)$ The result can be used to perform a $t$-test comparing the value of the index with twice its standard deviation, which, under the assumption of normality, is a test at the $5 \%$ significance level. Significant values of the test indicate that the observed degree of concentration deviates significantly from a situation of random location of the firms.

${ }^{10}$ An Annex with the full set of results is available online. 
${ }^{11}$ Results are presented in the paper only for functional regions. However, we computed the measure for Italian provinces (NUTS-3) and regions (NUTS-2). The Annex available online contains the full set of results.

${ }^{12}$ However, in the last years, thanks to the financial and fiscal incentives available to the Objective 1 regions, FIAT has decentralized part of its production in the southern regions of Italy.

13 The concept of the 'Third Italy' was introduced in the late 1970s. At that time, it became apparent that little economic progress was realized in the South ('Second Italy'), and that the traditionally rich Northwest ('First Italy') was facing a deep crisis, while in contrast the Northeast and centre of Italy showed fast growth.

${ }^{14}$ By convention, the diagonal elements of the weights matrix are set to zero.

${ }^{15}$ We checked for the robustness of the results reported in the paper. More specifically, we repeated the exercise using spatial weights matrices based on the squared of the inverse distance between pairs of locations (with different threshold levels), and on first-order contiguity. The Annex available online contains the results of the sensitivity analysis performed on the different spatial weight matrices.

${ }^{16}$ Inference is based on 999 permutations at the 0.05 significance level.

17 Amongst others, we find applications of local indicators of spatial association for the analysis of the distribution of regional income and structural funds in Europe (DALL'ERBA, 2005), and for the study of local agglomeration patterns in Paris and its surroundings (GUILLAIN and LE GALLO, 2010).

${ }^{18}$ The Annex available online contains the results for all sectors. 
${ }^{19}$ The traditional sectors consist of the low-technology manufacturing and the medium-low technology manufacturing.

${ }^{20}$ In Italy, the district model consists of a high concentration of small firms, specialized in the production of a specific item and grouped together in the same territorial area. For additional information on industrial districts in Italy and for an overview of their history and main production activities, see www.distretti.org.

${ }^{21}$ Sectors $16,17,18,19,20,21,23,25,26,27,28,29,30,33,34,35,36,37,52,55,60$, $61,63,64,66,73$, and 71 .

${ }^{22}$ Sectors $15,22,24,31,32,40,41,45,50,51,62,65,67,70,72$, and 74 . 
APPENDIX

Table A1. List of sectors and NACE-codes

\begin{tabular}{|c|c|}
\hline 2-digit NACE & Sector \\
\hline 15 & Manufacture of food products and beverages \\
\hline 16 & Manufacture of tobacco products \\
\hline 17 & Manufacture of textiles \\
\hline & Manufacture of wearing apparel; dressing and \\
\hline 18 & dyeing... \\
\hline 19 & Tanning and dressing of leather \\
\hline 20 & Manufacture of wood and of products of wood... \\
\hline 21 & Manufacture of pulp, paper and paper products \\
\hline 22 & $\begin{array}{l}\text { Publishing, printing and reproduction of recorded } \\
\text { media }\end{array}$ \\
\hline 23 & Manufacture of coke, refined petroleum products... \\
\hline 24 & Manufacture of chemicals and chemical products \\
\hline 25 & Manufacture of rubber and plastic products \\
\hline 26 & $\begin{array}{l}\text { Manufacture of other non-metallic mineral } \\
\text { products }\end{array}$ \\
\hline 27 & Manufacture of basic metals \\
\hline 28 & $\begin{array}{l}\text { Manufacture of fabricated metal products, } \\
\text { except... }\end{array}$ \\
\hline 29 & Manufacture of machinery and equipment n.e.c. \\
\hline 30 & $\begin{array}{l}\text { Manufacture of office machinery and computers } \\
\text { Manufacture of electrical machinery and apparatus }\end{array}$ \\
\hline 31 & n.e.c. \\
\hline 32 & $\begin{array}{l}\text { Manufacture of radio, television and } \\
\text { communication... }\end{array}$ \\
\hline 33 & Manufacture of medical, precision and optical... \\
\hline 34 & Manufacture of motor vehicles, trailers... \\
\hline 35 & Manufacture of other transport equipment \\
\hline 36 & Manufacture of furniture; manufacturing n.e.c. \\
\hline 37 & Recycling \\
\hline 45 & Construction \\
\hline 50 & Sale, maintenance and repair of motor vehicles... \\
\hline 51 & $\begin{array}{l}\text { Wholesale trade and commission trade, except of } \\
\text { motor... }\end{array}$ \\
\hline 52 & Other wholesale \\
\hline 55 & Hotels and restaurants \\
\hline 60 & Land transport; transport via pipelines \\
\hline 61 & Water transport \\
\hline 62 & Air transport \\
\hline 63 & $\begin{array}{l}\text { Supporting and auxiliary transport activities; } \\
\text { activities. }\end{array}$ \\
\hline 64 & Post and telecommunications \\
\hline
\end{tabular}




\section{REFERENCES}

AIGINGER K. and DAVIES S. W. (2004) Industrial specialisation and geographic concentration: two sides of the same coin? Not for the European Union, Journal of Applied Economics 7, 231-248.

ALECKE B., ALSLEBEN C., SCHARR F. and UNTIEDT G. (2006) Are there really hightech clusters? The geographic concentration of German manufacturing industries and its determinants, Annals in Regional Science 40, 19-42.

\section{ALONSO-VILLAR O., CHAMORRO-RIVAS J. M. and GONZALEZ-CERDEIRA X.} (2004) Agglomeration economies in manufacturing industries: the case of Spain, Applied Economics 36, 2103-2116.

ANSELIN L. (1988) Spatial Econometrics: Methods and Models. Kluwer, Dordrecht.

ANSELIN L. (1995) Local indicators of spatial association - LISA, Geographical Analysis 27, 93-115.

ARBIA G. (2001) The role of spatial effects in the empirical analysis of regional concentration, Journal of Geographical Systems 3, 271-281.

ARBIA G. and ESPA G. (1996) Statistica Economica Territoriale. Cedam, Padua. 
ARBIA G., ESPA G. and QUAH, D. (2008) A class of spatial statistical methods in the empirical analysis of spatial clusters, Empirical Economics 34, 81-103.

BERTINELLI L. and DECROP J. (2005) Geographical agglomeration: Ellison and Glaeser's index applied to the case of Belgian manufacturing industry, Regional Studies 39, 567-583.

BRÜLHART M. and TRAEGER R. (2005) An account of geographic concentration patterns in Europe, Regional Science and Urban Economics 35, 597-624.

CAMAGNI R. and CAPELLO R. (1999) Innovation and performance of SMEs in Italy: the relevance of spatial aspects, in FISCHER M. M., SUAREZ-VILLA L. and STEINER M. (Eds) Innovation, Networks and Localities. Springer-Verlag, Berlin.

COMBES P. and OVERMAN H. G. (2004) The spatial distribution of economic activities in the European Union, in HENDERSON J. V. and THISSE J.-F. (Eds) Handbook of Regional and Urban Economics. Elsevier, Amsterdam.

CRESSIE N. A. C. (1991) Statistics for Spatial Data. Wiley, New York.

DALL'ERBA S. (2005) Distribution of regional income and regional funds in Europe 1989-1999: an exploratory spatial data analysis, Annals in Regional Science 39, 121-148.

DE GROOT H. L. F., SMIT M. J. and POOT J. (2009) Agglomeration externalities, innovation and regional growth: theoretical perspectives and meta-analysis, in CAPELLO R. and Nijkamp P. (Eds) Handbook of Regional Growth and Development Theories. Edward Elgar Publishing, Cheltenham, UK. 
DEVEREUX M. P., GRIFFITH R. and SIMPSON H. (2004) The geographic distribution of production activity in the UK, Regional Science and Urban Economics 34, 533564.

DUMAIS G., ELLISON G. and GLAESER E. L. (2002) Geographic concentration as a dynamic process, Review of Economics and Statistics 84, 193-204.

DURANTON G. and OVERMAN H. G. (2005) Testing for localization using microgeographic data, Review of Economic Studies 72, 1077-1106.

ELLISON G. and GLAESER E. L. (1997) Geographic concentration in U.S. manufacturing industries: a dartboard approach, Journal of Political Economy 105, 899-927.

ELLISON G., GLAESER E. L. and KERR W. R. (2010) What causes industry agglomeration? Evidence from coagglomeration patterns, American Economic Review 100, 1195-1213.

FUJITA M. and THISSE J.-F. (2002) Economics of Agglomeration: Cities, Industrial Location and Regional Growth. Cambridge University Press, Cambridge, UK.

FUJITA M. and THISSE J.-F. (2009) New economic geography: an appraisal on the occasion of Paul Krugman's 2008 Nobel Prize in economic sciences, Regional Science and Urban Economics 39, 109-119.

GUILLAIN R. and LE GALLO J. (2010) Agglomeration and dispersion of economic activities in and around Paris: an exploratory spatial data analysis, Environment and Planning B: Planning and Design 37, 961-981.

HAALAND J. I., KIND H. J., MIDELFART KNARVIK K. E. and TORSTENSSON J. (1999) What Determines the Economic Geography of Europe? CEPR Discussion Paper no. 2072, London. 
KIM S. (1995) Expansion of markets and the geographical distribution of economic activities: the trends in the U.S. manufacturing industries, 1860-1987, Quarterly Journal of Economics 110, 881-908.

KRUGMAN P. (1991) Geography and Trade. MIT Press, Cambridge, MA.

LAFOURCADE M. and MION G. (2007) Concentration, agglomeration and the size of plants, Regional Science and Urban Economics 37, 46-68.

LE GALLO J. and ERTUR C. (2003) Exploratory spatial data analysis of the distribution of regional per capita GDP in Europe, 1980-1995, Papers in Regional Science 82, 175-201.

MAGGIONI M. A. (2002) Clustering Dynamics and the Location of High-tech Firms. Springer, Heidelberg.

MARCON E. and PUECH F. (2003) Evaluating the geographic concentration of industries using distance-based measures, Journal of Economic Geography 3, 409-428.

MARSHALL A. (1890) Principles of Economics. MacMillan, London.

MAUREL F. and SEDILLOT B. (1999) A measure of the geographic concentration in French manufacturing industries, Regional Science and Urban Economics 29, 575604.

MIDELFART-KNARVIK K. H., OVERMAN H. G., REDDING S. G. and VENABLES A. G. (2004) The location of European industry, in DIERX A. H., ILZKOVITZ F. and SEKKAT K. (Eds) European Integration and the Functioning of Product Markets. Edward Elgar Publishing, Cheltenham, UK.

MORAN P. A. P. (1950) Notes on continuous stochastic phenomena, Biometrika 37, 1723. 
MORI T., NISHIKIMI K. and SMITH T. E. (2005) A divergence statistic for industrial localization, Review of Economics and Statistics 87, 635-651.

O’DONOGHUE D. and GLEAVE B. (2004) A note on methods for measuring industrial agglomeration, Regional Studies 38, 419-427.

PIRAS G. and ARBIA G. (2009) A new class of spatial concentration measures, Computational Statistics and Data Analysis 53, 4471-4481.

QUAH D. and SIMPSON H. (2003) Spatial Cluster Empirics. London School of Economics Working Paper Series, no. 200306, London.

ZHANG T. and LIN G. (2007) A decomposition of Moran's I for clustering detection, Computational Statistics and Data Analysis 51, 6123-6137. 


\section{TABLES}

Table Error! Main Document Only.. Average values of the Ellison-Glaeser index in 1991

and 2001

\begin{tabular}{lcccccc}
\hline & \multicolumn{2}{c}{ LLSs } & \multicolumn{2}{c}{ NUTS-3 (provinces) } & \multicolumn{2}{c}{ NUTS-2 (regions) } \\
\hline \hline & 1991 & 2001 & 1991 & 2001 & 1991 & 2001 \\
\hline Manufacturing & 0.024 & 0.015 & 0.027 & 0.023 & 0.042 & 0.041 \\
Service & 0.018 & 0.024 & 0.018 & 0.037 & 0.020 & 0.034 \\
& & & & & & \\
\hline
\end{tabular}


Table Error! Main Document Only.. Ellison-Glaeser index for 15 most concentrated industries in 1991 and 2001

\begin{tabular}{|c|c|c|c|c|c|}
\hline 2-digit & sector & $\begin{array}{c}\gamma_{E G} \\
1991\end{array}$ & $\begin{array}{l}\text { Rank } \\
1991\end{array}$ & $\begin{array}{c}\gamma_{E G} \\
2001\end{array}$ & $\begin{array}{l}\text { Rank } \\
2001\end{array}$ \\
\hline 34 & Manufacture of motor vehicles & 0.145 & 1 & 0.061 & 3 \\
\hline 30 & $\begin{array}{l}\text { Manufacture of office } \\
\text { machinery and computers }\end{array}$ & 0.131 & 2 & - & - \\
\hline 61 & Water transport & 0.087 & 3 & 0.072 & 2 \\
\hline 66 & Insurance and pension funding & 0.063 & 4 & 0.073 & 1 \\
\hline 73 & Research and development & 0.047 & 5 & 0.026 & 7 \\
\hline 24 & $\begin{array}{l}\text { Manufacture of chemicals and } \\
\text { chemical products }\end{array}$ & 0.034 & 6 & 0.028 & 6 \\
\hline 32 & $\begin{array}{l}\text { Manufacture of radio, } \\
\text { television and communications }\end{array}$ & 0.029 & 7 & 0.021 & 9 \\
\hline 17 & Manufacture of textiles & 0.029 & 8 & 0.034 & 4 \\
\hline 22 & $\begin{array}{l}\text { Publishing, printing and } \\
\text { reproduction }\end{array}$ & 0.026 & 9 & - & - \\
\hline 19 & $\begin{array}{l}\text { Tanning and dressing of } \\
\text { leather }\end{array}$ & 0.026 & 10 & 0.034 & 5 \\
\hline 72 & Computer and related activities & 0.016 & 11 & 0.022 & 8 \\
\hline 27 & Manufacture of basic metals & 0.015 & 12 & 0.016 & 11 \\
\hline 23 & $\begin{array}{l}\text { Manufacture of coke, refined } \\
\text { petroleum products }\end{array}$ & 0.014 & 13 & - & - \\
\hline 36 & Manufacture of furniture & 0.013 & 14 & 0.016 & 13 \\
\hline 37 & $\begin{array}{l}\text { Manufacture of other transport } \\
\text { equipment }\end{array}$ & 0.013 & 15 & 0.014 & 15 \\
\hline 22 & $\begin{array}{l}\text { Publishing. printing, and } \\
\text { reproduction }\end{array}$ & - & - & 0.016 & 10 \\
\hline 16 & $\begin{array}{l}\text { Manufacture of tobacco } \\
\text { products }\end{array}$ & - & - & 0.016 & 12 \\
\hline 26 & $\begin{array}{l}\text { Manufacture of other non- } \\
\text { metallic mineral products }\end{array}$ & - & - & 0.015 & 14 \\
\hline
\end{tabular}


Table Error! Main Document Only.. Moran's I for 15 most spatially autocorrelated industries in

\begin{tabular}{|c|c|c|c|c|c|c|}
\hline Rank & Standard LQ & Moran's I & $\begin{array}{c}\text { Adjusted-LQ } \\
\text { (Threshold: } 50 \text { employees) }\end{array}$ & Moran's I & $\begin{array}{c}\text { Adjusted-LQ } \\
\text { (Threshold: } 10 \text { employees) }\end{array}$ & Moran's 1 \\
\hline 1 & Real estate activities & 0.625 & Real estate activities & 0.629 & $\begin{array}{l}\text { Tanning and dressing of } \\
\text { leather }\end{array}$ & 0.514 \\
\hline 2 & Other wholesale & 0.560 & Other wholesale & 0.579 & $\begin{array}{l}\text { Manufacture of food } \\
\text { products and beverages }\end{array}$ & 0.340 \\
\hline 3 & $\begin{array}{l}\text { Tanning and dressing } \\
\text { of leather }\end{array}$ & 0.527 & $\begin{array}{l}\text { Tanning and dressing of } \\
\text { leather }\end{array}$ & 0.568 & $\begin{array}{l}\text { Manufacture of machinery } \\
\text { and equipment n.e.c. }\end{array}$ & 0.290 \\
\hline 4 & $\begin{array}{l}\text { Manufacture of } \\
\text { machinery and } \\
\text { equipment n.e.c. }\end{array}$ & 0.417 & $\begin{array}{l}\text { Post and } \\
\text { telecommunications }\end{array}$ & 0.490 & $\begin{array}{l}\text { Manufacture of wood and of } \\
\text { products of wood... }\end{array}$ & 0.269 \\
\hline 5 & $\begin{array}{l}\text { Hotels and } \\
\text { restaurants }\end{array}$ & 0.384 & $\begin{array}{l}\text { Manufacture of machinery } \\
\text { and equipment n.e.c. }\end{array}$ & 0.455 & $\begin{array}{l}\text { Sale, maintenance and repair } \\
\text { of motor vehicles... }\end{array}$ & 0.268 \\
\hline 6 & $\begin{array}{l}\text { Manufacture of } \\
\text { fabricated metal } \\
\text { products, except... }\end{array}$ & 0.379 & $\begin{array}{l}\text { Manufacture of wearing } \\
\text { apparel; dressing and } \\
\text { dyeing... }\end{array}$ & 0.424 & $\begin{array}{l}\text { Manufacture of wearing } \\
\text { apparel; dressing and } \\
\text { dyeing... }\end{array}$ & 0.267 \\
\hline 7 & $\begin{array}{l}\text { Manufacture of } \\
\text { wearing apparel; } \\
\text { dressing and } \\
\text { dyeing... }\end{array}$ & 0.372 & Hotels and restaurants & 0.408 & Hotels and restaurants & 0.258 \\
\hline 8 & $\begin{array}{l}\text { Sale, maintenance } \\
\text { and repair of motor } \\
\text { vehicles... }\end{array}$ & 0.335 & $\begin{array}{l}\text { Manufacture of fabricated } \\
\text { metal products, except... }\end{array}$ & 0.395 & $\begin{array}{l}\text { Manufacture of fabricated } \\
\text { metal products, except... }\end{array}$ & 0.256 \\
\hline 9 & $\begin{array}{l}\text { Wholesale trade and } \\
\text { commission trade, } \\
\text { except of motor... }\end{array}$ & 0.312 & $\begin{array}{l}\text { Sale, maintenance and } \\
\text { repair of motor vehicles... }\end{array}$ & 0.353 & Other wholesale & 0.232 \\
\hline 10 & $\begin{array}{l}\text { Manufacture of } \\
\text { furniture; } \\
\text { manufacturing n.e.c. }\end{array}$ & 0.273 & $\begin{array}{l}\text { Wholesale trade and } \\
\text { commission trade, except } \\
\text { of motor... }\end{array}$ & 0.331 & $\begin{array}{l}\text { Manufacture of electrical } \\
\text { machinery and apparatus } \\
\text { n.e.c. }\end{array}$ & 0.206 \\
\hline 11 & $\begin{array}{l}\text { Manufacture of } \\
\text { medical, precision } \\
\text { and optical... }\end{array}$ & 0.263 & $\begin{array}{l}\text { Financial intermediation, } \\
\text { except insurance and } \\
\text { pension... }\end{array}$ & 0.330 & Manufacture of basic metals & 0.199 \\
\hline 12 & $\begin{array}{l}\text { Activities auxiliary to } \\
\text { financial } \\
\text { intermediation }\end{array}$ & 0.234 & $\begin{array}{l}\text { Manufacture of medical, } \\
\text { precision and optical... }\end{array}$ & 0.309 & $\begin{array}{l}\text { Manufacture of other } \\
\text { transport equipment }\end{array}$ & 0.182 \\
\hline 13 & $\begin{array}{l}\text { Manufacture of } \\
\text { textiles }\end{array}$ & 0.227 & $\begin{array}{l}\text { Manufacture of wood and } \\
\text { of products of wood... }\end{array}$ & 0.303 & Post and telecommunications & 0.177 \\
\hline 14 & $\begin{array}{l}\text { Manufacture of wood } \\
\text { and of products of } \\
\text { wood... }\end{array}$ & 0.195 & $\begin{array}{l}\text { Manufacture of furniture; } \\
\text { manufacturing n.e.c. }\end{array}$ & 0.299 & Manufacture of textiles & 0.161 \\
\hline 15 & Construction & 0.191 & $\begin{array}{l}\text { Manufacture of basic } \\
\text { metals }\end{array}$ & 0.274 & $\begin{array}{l}\text { Manufacture of medical, } \\
\text { precision and optical... }\end{array}$ & 0.144 \\
\hline
\end{tabular}

Notes: The spatial weights are based on the five nearest neighbours. All values of the

Moran's $I$ are significant with $p$-values $<0.001$. 
FIGURES
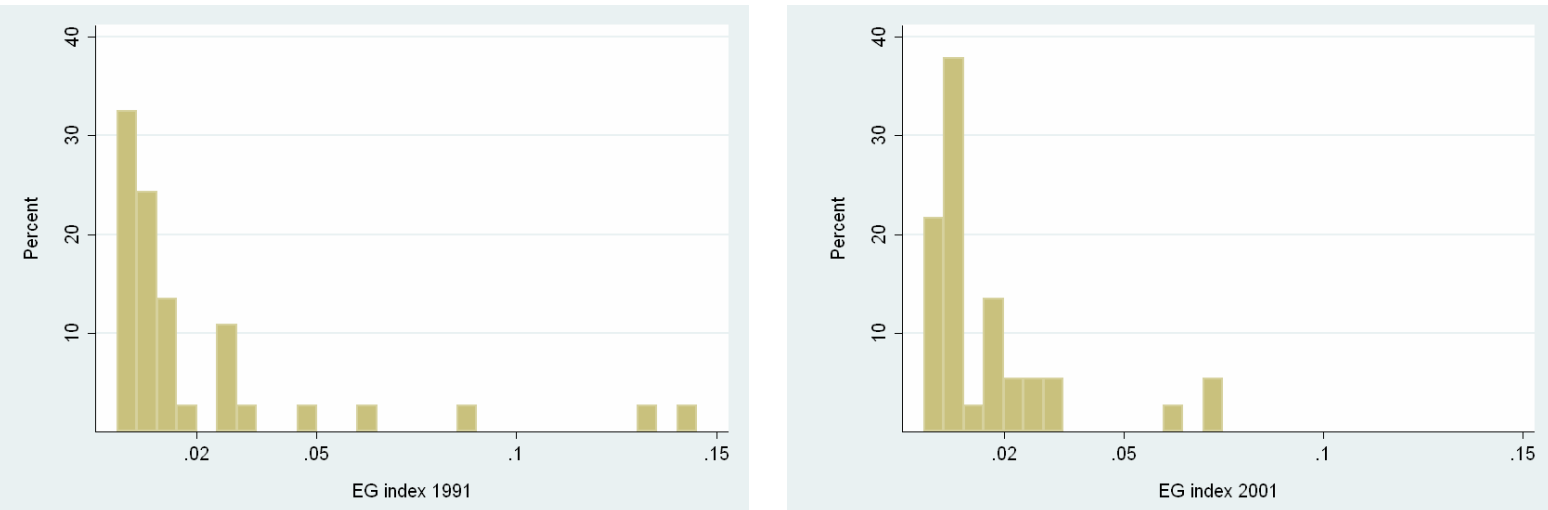

Fig. Error! Main Document Only.. Overall distribution of industrial concentration in Italy (EG index) in 1991 and 2001 
Fig. Error! Main Document Only.. Local Moran's I cluster maps for Manufacture of

\section{Textile}

Note: Standard LQ at the top, Adjusted LQ with firm size up to 50 at the bottom left, and with firm size up to 10 at the bottom right. High-High is indicated in red, High-Low in pink, Low-Low in dark blue, and Low-High in light blue 

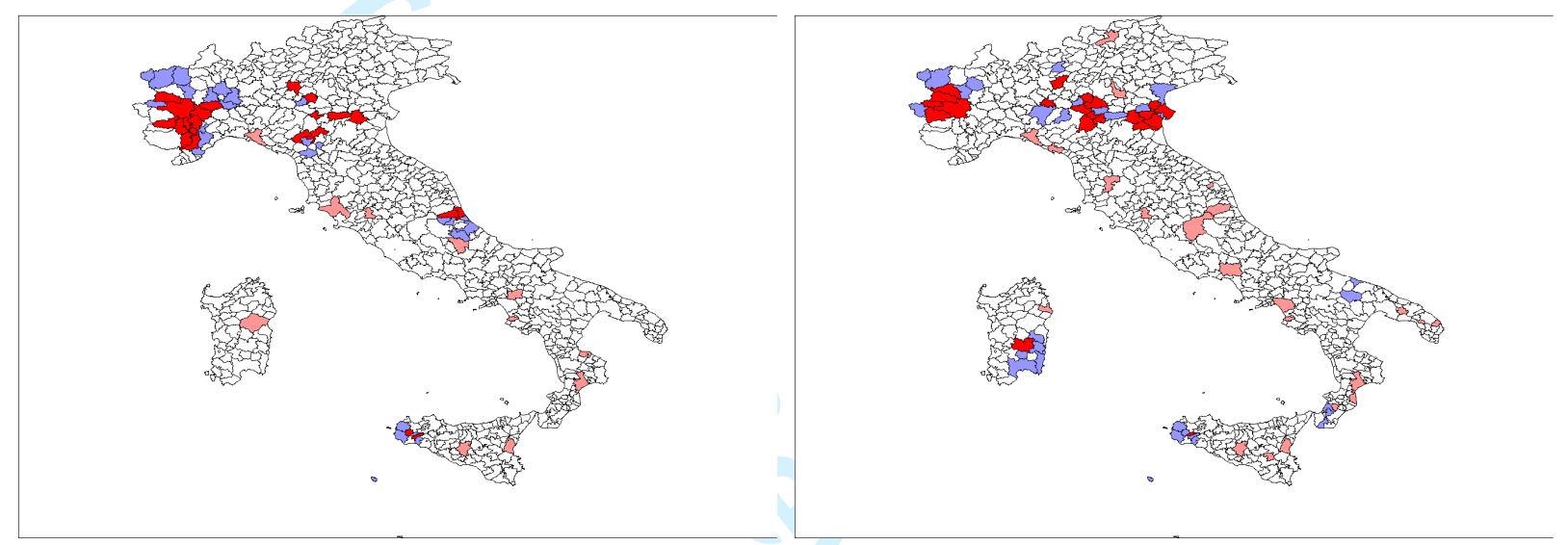

Fig. Error! Main Document Only.. Local Moran's I cluster maps for Manufacture of Motor Vehicle

Note: Standard LQ at the top, Adjusted LQ with firm size up to 50 at the bottom left, and with firm size up to 10 at the bottom right. High-High is indicated in red, High-Low in pink, Low-Low in dark blue, and Low-High in light blue 

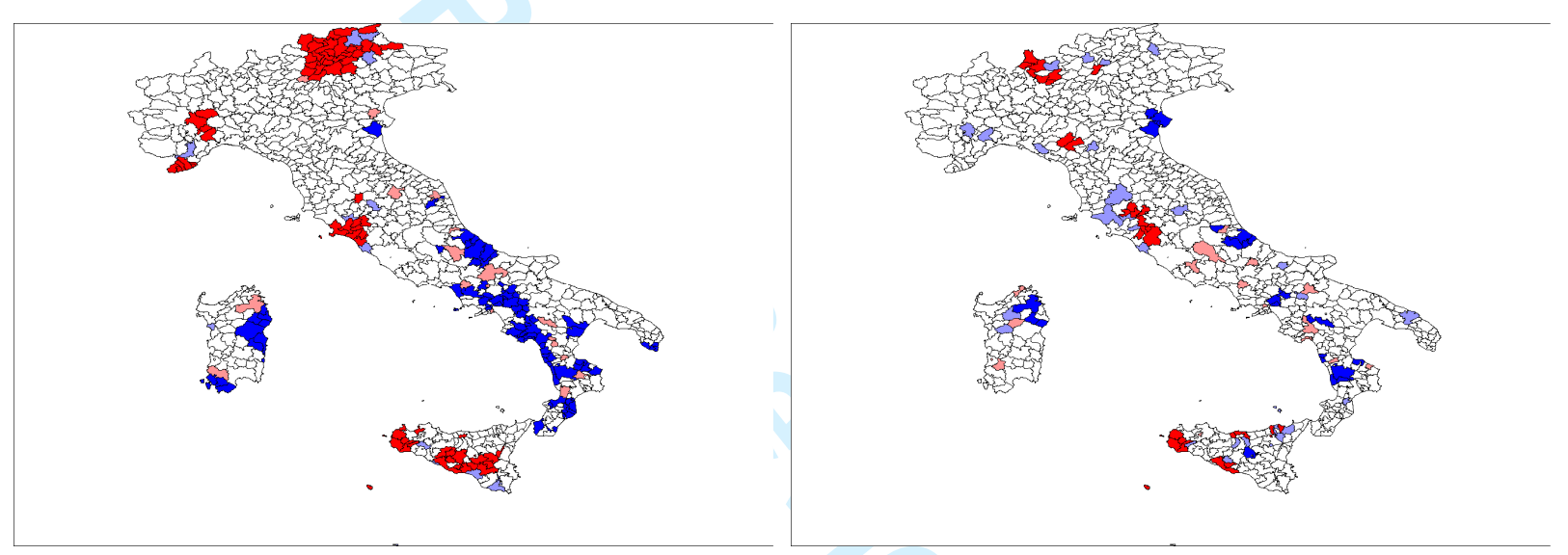

Fig. Error! Main Document Only.. Local Moran's I cluster maps for Financial

\section{Intermediation}

Note: Standard LQ at the top, Adjusted LQ with firm size up to 50 at the bottom left, and with firm size up to 10 at the bottom right. High-High is indicated in red, High-Low in pink, Low-Low in dark blue, and Low-High in light blue 

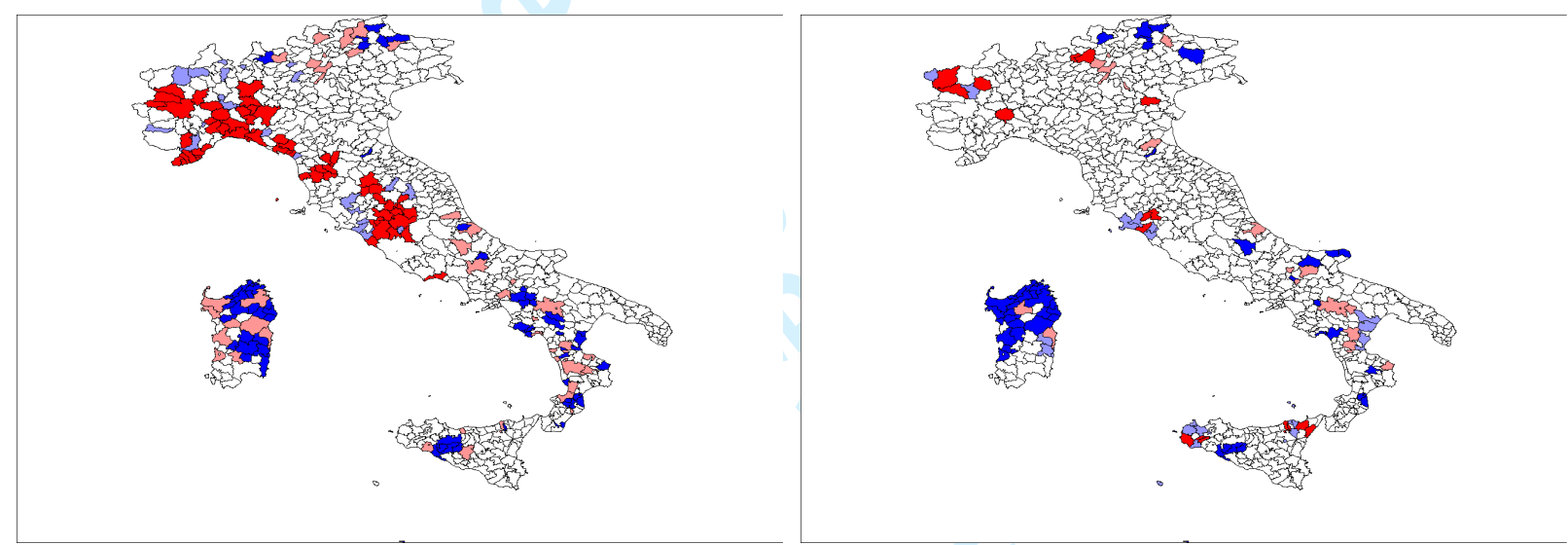

Fig. Error! Main Document Only.. Local Moran's I cluster maps for Activities auxiliary to financial intermediation

Note: Standard LQ at the top, Adjusted LQ with firm size up to 50 at the bottom left, and with firm size up to 10 at the bottom right. High-High is indicated in red, High-Low in pink, Low-Low in dark blue, and Low-High in light blue 
2

3

4

5

6

10

11

12

13

14

15

16

17

18

19

20

21

22

23

24

25

26

27

28

29

30

31

32

33

34

35

36

37

38

39

40

41

42

43

44

45

46

47

48

49

50

51

52

53

54

55

56

57

58

59

60 